\title{
El regreso de los judíos hispanos a Tierra Santa
}

\author{
EnRIQUe CANTERA MONTENEGRO \\ UNED
}

\begin{abstract}
RESUMEN ABSTRACT
Tras un breve análisis acerca del lugar que la ciudad de Jerusalén y la Tierra Prometida ocupan en el judaismo y en la conciencia colectiva del pueblo judío, y del papel que la Ciudad Santa desempeña como meta de los peregrinos judios, se estudian los movimientos de migración de

los judios hispanos hacia Palestina, a to largo de la Edad Media y hasta el siglo xvil.

After a brief analysis about the importance of Jerusalem and the Promised Land in the Judaism and in the collective consciousness of the Jewish people, and the role played by the Holy City as a destination for the Jewish pilgrims, the migration movements of the Spanish Jewish to Palestine are studied, along the Middle Ages, until the 17 th century.
\end{abstract}

\section{PALABRAS CLAVE}

Jerusalén, Palestina. Tierra Santa, peregrinación, sefardies, emigracióninmigración, mesianismo.

\section{KEYWORDS}

Jerusalem, Palestine, Holy Land, pilgrimage, shephardics, emigrationinmigration, mesianism.

\section{INTRODUCCIÓN: JERUSALÉN Y LA TIERRA PROMETIDA EN LA CONCIENCIA COLECTIVA DEL PUEBLO JUDIO}

Parece fuera de cualquier duda que entre las grandes religiones monoteistas el judaísmo es la que está más estrechamente vinculada a un territorio concreto: la Tierra Prometida o Tierra de Israel (Eretz Yisrael ${ }^{1}$, y, más en particular, la ciudad de Jerusaién. Como acertadamente señala Kristel Stendahl,

A lo largo del trabajo utilizo, preferentemente, el término Palestina, más habitual en la historiografia española 
"Para los cristianos y mahometanos, el término Lugares Santos es una expresión adecuada de aquello que tiene importancia para ellos. Aquí se encuentran lugares sagrados, rodeados por el aura de los acontecimientos más santos, aqui se encuentran los lugares de peregrinaje, el verdadero centro de devoción más elevada, pero para el judaismo es diferente. Los lugares sagrados del judaísmo no poseen santuarios, su religión no está ligada a lugares, sino a la tierra; no a to que habia ocurrido en Jerusalén, sino a Jerusalén mismo. Jerusalén como lugar de peregrinación para todos los judios existe también después de su destrucción, también en nuestros dias"?

Desde los tiempos del rey David ( $c^{a} 1010-970$ a.C.), Jerusalén se convirtió en el auténtico centro del judaismo, tanto desde el punto de vista religioso y ritual como del político, y en la referencia más importante para el pueblo hebreo. El lugar que esta ciudad ocupa en la conciencia colectiva del pueblo judío se refuerza por el hecho de que es considerada morada de Yahveh, el Señor, lo que le otorga el carácter de ciudad santa y de vínculo de unión entre Dios y los hombres $^{3}$.

Al mismo tiempo, la preferencia de Dios por Jerusalén, y la presencia divina (en hebreo shekinah) en el Templo, guardan estrecha relación con la residencia en esta ciudad del pueblo de Israel, del "pueblo elegido". En palabras de Elio Passeto, la razón principal por la que Yahveh escoge Jerusalén como su morada terrenal es su pueblo, y es a través de él como se hace presente en el mundo ${ }^{4}$. Así, por tanto, el papel trascendental que, desde la óptica judía, desempeña Jerusalén en la historia de la humanidad, se encuentra en estrecha relación con la fusión en ella de tres principios fundamentales: Dios, el pueblo de Israel y la Tierra Prometida.

En definitiva, Jerusalén ha sido siempre, a través de las generaciones, y en las más diversas circunstancias históricas, el auténtico centro de la vivencia judía, de forma que esta ciudad aparece íntimamente ligada al concepto judío de salvación. Considerada punto de convergencia entre el cielo y la tierra, el papel que se le reserva en el futuro es el de germen del proceso de unión entre todas las naciones. La noción de Jerusalén como ciudad universal y patrimonio de todos los hombres se reforzaba entre los judíos por el hecho de que nunca había sido dividida entre

Kristel Stendahl es profesor de Religiones Comparadas en la Universidad de Harvard

Cita tomada de Rabino Dr. Esteban VEGHAZIK, «El significado de Jerusalén para los judios», en El Olivo, XX, 43-44 (1996), págs. 205-216 (en concreto, pag. 212).

${ }^{3}$ El carácter sagrado de la tierra de Israel se manifestaba de múltiples maneras: en el respeto con el que los sabios y los maestros de la Ley besaban las piedras de Tierra Santa; en la afirmación de algunos rabinos de que los pecados de quienes residian en Israel se perdonarian más fácilmente; o en la creencia común de que la venida del Mesias se manifestaría antes en Israel que en cualquier otro lugar. Todo ello empujaria a numerosos judios a emigrar desde sus lugares de residencia a Palestina, no tanto para vivir en esta tierra como para morir en ella y figurar, por tanto, entre los primeros que resucitarían tras la venida del Mesias. De este modo, a lo largo de la Edad Media fue comun entre los judios el convencimiento más absoluto acerca de la primacia religiosa de quienes residian en la Tierra Prometida y, más en concreto, en la ciudad santa de Jerusalén.

"Elio PASSETO, «El significado de Jerusalén en la Biblia y en la tradición de Israel», en El Olivo, XX, 43-44 (1996), págs. 153-174 (en concreto, pág. 157). 
las distintas tribus de Israel por lo que, de hecho y de derecho, pertenecía por igual a todo el pueblo hebreo.

Esta unión íntima y especial entre el pueblo judio, por una parte, y la Tierra Prometida y Jerusalén, por otra, perduró a través de los tiempos, y a pesar del exilio, y ello por dos motivos, principalmente. En primer lugar porque, al verse privados en el exilio de los derechos y de las prerrogativas inherentes a la ciudadania, se incrementó en los judíos el sentimiento de añoranza por Israel. $Y$, en segundo lugar, porque a través de la fe y la doctrina, expresadas en las enseñanzas que les instruían en la religión y en las oraciones que recitaban a diario, los judios se consideraban residentes despojados de la Tierra Prometida, aunque sólo circunstancialmente, porque la consideraban como propia y vivian con la permanente esperanza de retornar a ella ${ }^{5}$. De este modo, aunque aceptaban el exilio como una manifestación más de la voluntad divina, confiaban también firmemente en la promesa divina de que un dia retornarian a Israel; y esta esperanza fue lo que les otorgó la necesaria fortaleza de ánimo para afrontar las penalidades y los sufrimientos derivados del exilio.

Por todo ello, a través de las generaciones, Jerusalén permaneció viva en la memoria colectiva del pueblo judio en el exilio, que a diario recuerda a la ciudad santa en las oraciones y en las bendiciones que jalonan su vida cotidiana. Así en la oración judía por excelencia, el Shemah Yisra'el (= Escucha Israel) ${ }^{6}$, en la bendición décimocuarta se implora a Yahveh con las siguientes palabras:

"Retorna con gracia a Jerusalén, tu ciudad, morando en ella como lo prometiste; reconstrúyela pronto, aún en nuestros días, cual reconstrucción perenne, restableciendo en ella el trono de David. Bendito seas, oh Señor, constructor de Jerusalén».

Especial significación encierra la frase que se pronuncia al concluir el séder de Pésah", "el año que viene en Jerusalén", que no sólo es expresión de la esperanza de un inmediato retorno a la Jerusalén restaurada de la era mesiánica, sino también de la confianza en alcanzar la Jerusalén celestial ${ }^{8}$.

En definitiva, se procuraba que a través de la oración, que constituía la conciencia religiosa del pueblo hebreo que vivia en el exilio, lejos de Israel, los fie-

Rabino Dr. Esteban VEGHAZIK, “El significado de Jerusalén para los judíos», pág. 206.

- Oracion que recoge los principios fundamentales de la religion judia, y en la que se afirma de forma indubitable la unicidad divina. Debe ser recitada por los judios al menos dos veces al dia, por la mañana y por la noche.

7 Cena ritual que se celebra en todos los hogares judios la noche en que se inicia la fiesta de la Pascua, y cuya estructura está minuciosamente fijada en la Mishnah (código legal rabínico, elaborado a base de una compilación de leyes orales. La redacción definitiva la llevó a cabo Yehudah ha-Nasi, alrededor del año 200 d.C.).

${ }^{8}$ El concepto de una Jerusalén celestial fue desarrollado por el judaismo rabínico en el periodo intertestamentario. Según un pasaje del Midrash (interpretación de la Escritura, cuya finalidad consiste en desvelar el significado pleno de la ley biblica y obtener de ella un principio moral o un concepto teológico), la Jerusalén celestial sería sólo un reflejo de la terrenal; debido a su gran amor por la Jerusalén terrenal, Dios habría construido otra ciudad igual en el cielo. Para otros autores judíos, por el contrario, la Jerusalén terrenal habria sido construida según el arquetipo de la ciudad celestial. 
les judios recordaran permanentemente a Jerusalén y mantuvieran la esperanza de retornar a la Tierra Prometida y de reconstruir la ciudad santa. El momento en el que esto tuviera lugar no era relevante, ya que lo que de verdad importaba era que el pueblo judío confiara en que esta esperanza se haría realidad.

\section{JERUSALEN, META DE LOS PEREGRINOS JUDIOS}

Coincidiendo con la designación de Jerusalén como la capital de los reinos judíos y con su conversión en el centro espiritual del judaísmo, acontecimientos que tuvieron lugar en los tiempos del rey David, esta ciudad se convirtió también en meta de las principales peregrinaciones judías.

La peregrinación a Jerusalén ${ }^{9}$ estaba vinculada en época biblica a las tres grandes fiestas de peregrinación del judaísmo, conocidas genéricamente como shalosh regalim, y que son la fiesta de Pésah o Pascua, que se celebra los días 14 a 21 del mes de nisan; Shavu'ot o fiesta de las Semanas, que se celebra el día 6 del mes de siván; y Sukkot o fiesta de los Tabernáculos, que se celebra los días 15 a 22 del mes de tishri. Los orígenes de estas peregrinaciones hay que buscarlos en los antiguos ritos agrícolas de los cananeos, quienes hacian ofrenda en sus templos de las primicias de los frutos de la tierra en las mismas épocas del año, es decir coincidiendo con el comienzo de la primavera, del verano y del otoño. Los peregrinos llegaban a Jerusalén desde los más diversos rincones de Palestina, y aún desde Babilonia, y en su viaje debian hacer frente a innumerables peligros; con el fin de facilitarles el viaje, las autoridades públicas promovian la reparación de las vías y caminos que conducian a Jerusalén y la excavación de pozos, procuraban facilitar el alojamiento de los peregrinos, y decretaban el fin del luto público desde treinta días antes del comienzo de la fiesta.

Las peregrinaciones continuaron tras la destrucción del Segundo Templo (70 d.C.) y el consiguiente éxodo del pueblo hebreo, aun cuando perdieron su inicial carácter alegre, el propio de una fiesta popular, y se convirtieron en una manifestación más de duelo por la ruina del Santuario. Así, cuando los peregrinos llegaban a las ruinas del Templo para orar ante el Muro de las Lamentaciones, se rasgaban las vestiduras en señal de aflicción y recitaban el versículo 64, 10 del profeta Isaías:

"Nuestra santa y hermosa Casa, donde nuestros padres Te alababan, fue quemada a fuego, y todas nuestras cosas valiosas fueron arrasadas".

Aun cuando el flujo de peregrinos no cesó en ningún momento, es indudable que la dispersión de los judios y la sujeción de Palestina al control político de Roma, primero, y de Bizancio, después, limitaron considerablemente los movi-

En hebreo, el concepto de peregrinación se designa con el término aliyyá, derivado del verbo 'alá, que significa subir, en alusión a la subida de los peregrinos a la ciudad y al Templo de Jerusalén. 
mientos hacia Tierra Santa. Sólo a partir de la conquista de Jerusalén por el sultán de Egipto y de Siria Saladino, en el año 1187, se suavizaron en alguna medida las condiciones que dificultaban la afluencia de los peregrinos judios, y se les permitió el acceso libre a sus Santos Lugares; no obstante, a lo largo de la Edad Media fue muy frecuente que los gobernadores cristianos o musulmanes de Tierra Santa obligaran a los peregrinos judios al pago de diversas tasas y gravámenes para permitirles el acceso a Jerusalén. En cualquier caso, y pese a las duras condiciones, las peregrinaciones no cesaron en ningún momento.

Pero si a lo largo de la Edad Media Jerusalén ostentó la primacía absoluta como centro de peregrinaciones judias, los hebreos del Próximo Oriente peregrinaban también, a imitación de los musulmanes, a las tumbas de algunos varones santos y a lugares con un protagonismo relevante en la historia bíblica. Eran centros de peregrinación en Palestina, entre otros, la ciudad de Burak, entre Jerusalén y Belén, donde los peregrinos acudían a visitar la tumba de Raquel, la esposa del patriarca Jacob; el monte Carmelo, en las proximidades de Haifa, en una de cuyas grutas la tradición afirmaba que el profeta Elías se había refugiado durante las persecuciones de Ajab; o Merom, junto a Safed, donde se recordaba al famoso tanna Simeón ben Yohay (siglo ॥ d.C.). Asimismo eran lugares de peregrinación en Mesopotamia el mausoleo del sumo sacerdote Yehoshua, en las proximidades de Bagdad; la supuesta tumba del profeta Ezequiel en Kefil; y la tumba de Ezra en Basora. En el Kurdistán se peregrinaba a las tumbas del profeta Daniel y de sus compañeros en Kerkuk, y a la gruta del profeta Elías en Bar Tanura; en Persia al mausoleo de Ester y Mardoqueo, en Hamadán; y en Egipto a la tumba de Jeremías, en Fostat ${ }^{10}$.

En el siglo $\mathrm{x}$ se poseen ya noticias documentales acerca de una peregrinación de judíos occidentales a Tierra Santa; es la peregrinación dirigida por el judío italiano Rabi Ahimaaz el Anciano, procedente de Venosa, pequeña localidad situada al sur de Foggia ${ }^{1}$.

Pero fue en el siglo $x$ cuando el caraismo, una herejía judia surgida en BabiIonia a mediados del siglo vill y que aspiraba a hacer de Jerusalén el centro neurálgico de su doctrina, impulsó un importante movimiento migratorio hacia esta ciudad, protagonizado por grupos de judios procedentes de diversos territorios sometidos políticamente al islam ${ }^{12}$.

10) Enciclopedia Judaica Castellana. México, 1948-1951, 11 vols. (en concreto, vol. pág. 381, voz «peregrinacion»).

11 Encyclopaedia Judaica. Jerusalem. Keter Publishing House Lłd., 16 vols. (en concreto, vol. 13, pág. 513, voz "pilgrimage").

12 El caraismo atacaba los cimientos mismos de la tradición judía; defendia la exclusiva validez de la Ley escrita y negaba, por tanto, cualquier valor a las enseñanzas de la Mishnah y del Talmud; acusaba al Talmud de haber desnaturalizado el judaismo. y defendia el retorno de la religión al texto de la Torah. Profundamente individualistas, racionalistas y ascéticos, los caraítas negaban también toda forma de autoridad humana, tradicional o institucional, que sería reemplazada por la decisión individual derivada de la aplicación del intelecto y de la conciencia a las Escrituras: asi, pues, para los caraitas el camino a seguir estaría marcado por la conciencia individual y no por las enseñanzas de los maestros. De este modo, 
Establecidos en buen número en Jerusalén ${ }^{13}$, vivían de forma austera, manifestando su pesar por la destrucción del Templo y rogando por su pronta restauración. Dentro del caraísmo de Jerusalén se desarrollaron posturas aún más radicales, como la encabezada por el persa Daniel al-Cumisí, quien consideraba que el único lugar santo en el mundo era la ciudad de Jerusalén, por lo que se oponía a la consagración de cualquier sinagoga en la Diáspora, porque para él y para sus seguidores no era posible santificar ningún lugar en tierra impura. Asimismo criticaba duramente a sus correligionarios judios, a los que acusaba de haber olvidado a Jerusalén por interesarse sólo por el lucro, más fácil de alcanzar en la Diáspora que en Israel. Con el fin de promover el traslado temporal a Jerusalén de un número importante de caraitas, al-Cumisi propuso la organización de una haluqqaho residencia para peregrinos, que dispondría de una financiación propia; asimismo animaba a que cada comunidad de la Diáspora enviara a cinco de sus miembros a la ciudad santa con lo suficiente para su mantenimiento, de forma que "estariamos asi unidos para rogar constantemente a nuestro Dios en las montañas de Jerusalén» ${ }^{14}$.

En cualquier caso, la inmensa mayoria de los judíos permaneció unida a la dirección y a la instrucción de los rabanitas, y fiel a la guia de las yeshibot ${ }^{15}$ de $\mathrm{Ba}$ bilonia y Palestina, de forma que la influencia caraíta, además de limitada, se diluyó progresivamente; a fines del siglo XII el caraísmo había desaparecido prácticamente de todas las comunidades judias europeas.

El movimiento de judíos desde Occidente hacia Palestina se incrementó de forma considerable a partir de los siglos de la Plenitud medieval. Simultáneamente, fue conformándose en la intelectualidad hebrea una interesante doctrina acerca del exilio y la redención, en relación con Israel, que tuvo algunos de sus más destacados representantes en Sefarad.

\section{LA CONFORMACIÓN EN LA INTELECTUALIDAD HISPANO-HEBREA DE UNA DOCTRINA DE REDENCIÓN EN RELACIÓN CON ISRAEL EN LOS SIGLOS XIIYXIII}

Entre los intelectuales sefardíes que dedicaron en su obra una atención especial a la Tierra Prometida y a la ciudad santa de Jerusalén como referentes fun-

el caraismo negaba toda autoridad religiosa a los rabinos y a los gaones, lo que ponia en serio peligro los cimientos socio-religiosos sobre los que se asentaba el judaísmo, por cuanto el gran logro y la razón de ser de las autoridades rabinicas habia sido la compilación de la Ley oral y su imposición como norma legal en la comunidad hebrea.

1. Eran conocidos como Abbelé Sión (= Los dolientes de Sión), Sosanim o Rosas (Haim Hillel BENSasson, Historia del pueblo judio. II. Edad Media. Madrid. Alianza Editorial, 1988, pág. 532).

14 H. H. Ben-Sasson, Op. cit, págs. 533-534.

1. Academias rabínicas para la formación bíblica y talmúdica. La institución de la yeshibah en el judaísmo medieval y moderno es una prolongación de la actividad de las academias de Babilonia y $\mathrm{Pa}$ lestina de los periodos talmúdico y gaónico 
damentales en el judaísmo, cabe destacar en primer lugar al médico, poeta y apologista Yehudah ha-Leví ( $\left.c^{a} 1070-1141\right)$, quien nació en Tudela y residió en distintas ciudades andaluzas, principalmente en la de Córdoba, de donde el sobrenombre de «el cordobés» con el que era conocido ${ }^{16}$. Como otros destacados representantes de la intelectualidad judía medieval, Ha-Levi se interesaba por el que consideraba inminente advenimiento del Mesias que, según una revelación que había recibido en sueños, tendría lugar en el año 1130. Pasada esta fecha sin que este acontecimiento tuviera lugar, Ha-Leví sufrió una profunda decepción, que le llevó a considerar que el error en los cálculos de predicción obedecía a sus pecados. Es muy probable que fuera en este momento cuando tomara la firme determinación de trasladarse a Tierra Santa, si bien no se puso en camino hasta el año 1140; tras permanecer unos meses en Egipto, donde compuso sus conocidos Poemas del mar y Poemas de Egipto, en los que expresa continuamente su anhelo por llegar a Palestina y su deseo de ser enterrado en Tierra Santa, en mayo de 1141 partió en barco desde Egipto hacia Palestina, perdiéndose desde este momento su rastro. Su muerte debió producirse entre mayo y fines de septiembre de 1141 , sin que pueda saberse a ciencia cierta si llegó a ver cumplido su deseo de alcanzar Jerusalén ${ }^{17}$.

Entre 1130 y 1140 redactó su obra apologética titulada El Kuzari (= El libro del Jázar), que está considerada como la más profunda de las apologías del judaísmo. En esta obra, Ha-Leví presenta al rey de los jázaros José consultando a un filósofo, a un cristiano, a un musulmán y a un judio, antes de decidirse a elegir una religión; convencido por los argumentos del judio, decidiría convertirse al judaísmo, y con él todo el pueblo jázaro ${ }^{18}$. En El Kuzari, Ha-Levi sintetiza bien la esencia de la religión judia, y se esfuerza por demostrar la superioridad del pueblo hebreo sobre

16 Para profundizar en el estudio de esta interesante figura de la cultura hispano-hebrea puede acudirse, entre otros muchos, a los estudios de José Ma MiLlás Val.licrosa, Yehudá ha-Levi como poeta y apologista. Madrid-Barcelona. C.S.I.C., 1947; Aviva Doron, Yehudah ha-Levi. Repercusión de su obra. Barcelona. Riopiedras Ediciones, 1985 (prólogo de Fernando Diaz Esteban en el que se hace una completa semblanza de Ha-Leví); Aurora SalvatierRa OSSORIO, La muerte, el destino y la entermedad en la obra poética de Y. Ha-Levi y S. Ibn Gabirol. Universidad de Granada, 1994; Ron BARKAI y Aviva DoRON «Mi corazón en el Oriente y yo lejos de la tierra de las palmeras. La poesía de añoranza andaluza musulmana y la poesía de Sión de Yehudah ha-Levi”, en Helmántica. 32, 1981, págs. 239-251; y Antonio ANTElo IGLESIAS, Judios españoles de la edad de oro (siglos Xl-Xil). Semblanzas, antologia y glosario. Madrid. Fundación Amigos de Sefarad-UNED, 1991 (págs. 197-253).

Su producción poética cuenta con una excelente edición en el libro titulado Yehuda ha-Levi. Poemas. Introducción, traducción y notas, Ángel Sáenz-Badillos y Judit Targarona Borrás. Estudios literarios, Aviva Dorón. Edición Bilingüe. Madrid. Clásicos Alfaguara, 1994

17 Una leyenda que recoge en el siglo xvi el judio italiano Rabi Gedalyah ben Yosef ibn Yahyá (1515 1578) en su Salselet ha-Qabbalah (= Cadena de la Tradición), presenta a Ha-Leví recitando su elegia “Sión, ¿es que no demandas?» frente a Jerusalén, cuando fue abatido por un jinete árabe. Sin embargo, el científico, exégeta y filósofo judio italiano Samuel David Luzzatto (1800-1865) rechaza la autenticidad de esta leyenda, señalando que en ese tiempo Jerusalén estaba bajo dominio cristiano y no musuimán; en su opinión. Ha-Levi debió morir en el desierto, antes de llegar a Tierra Santa.

18 Pueblo de origen turco que habitó en el sur del Cáucaso, de donde fueron expulsados por los musulmanes. Entre los sigios vII y $\times$ se establecieron en el curso bajo del rio Volga, donde fundaron un poderoso reino. La conquista por los rusos de la capital del reino jázaro Itil provocó la desaparición de este reino en el año 969 . 
los demás pueblos de la Tierra y el lugar central que ocupa Palestina en la historia de la humanidad, lo que le lleva a afirmar que es preferible vivir en Palestina, aun rodeado de paganos, que fuera de Tierra Santa, aun entre judíos. Para Díaz Esteban, esta "divinización» de Palestina puede guardar alguna relación con la arabiyya (= arabismo) islámica, para la que la mejor de todas las tierras era Arabia, y dentro de Arabia la tribu de Qurais, a la que pertenecía Mahoma ${ }^{19}$. Ha-Leví defiende asimismo la idea de que sólo en Tierra Santa es posible alcanzar la plenitud de la relación entre Yahveh y el pueblo elegido (shekinah), lo que explica su decidido propósito de trasladarse a Jerusalén para morir en la ciudad santa; esta actitud debe ser puesta en relación con las corrientes mesiánicas que por entonces se manifestaban con fuerza en el judaísmo hispano, y ha sido definida por Millás Vallicrosa como de «sionismo teológico» 20.

Yehudah ha-Leví compartía, así pues, un sentimiento muy extendido en el judaísmo medieval, que insistía en la santidad de Jerusalén; y a este sentimiento, y a su profunda fe mesiánica, responde la composición de unos poemas conocidos como Poemas de Sión (o Siónidas), en los que expresa su anhelo por llegar al monte Sión para orar ante las ruinas del Templo. Son unas composiciones que se alejan de la temática convencional de la época y que carecen de parangón en la poesía hebraico-andalusi; asi, aunque la expresión de añoranza por Israel es un tema habitual en la poesia religiosa hebrea, en el caso de HaLeví este sentimiento es algo más personal e intimo, de forma que el retorno a Tierra Santa adquiere en su obra una dimensión nueva. Como señala Aurora Salvatierra, en el ardiente deseo de Ha-Levi de trasladarse a Jerusalén se trasluce, además de un fuerte sentimiento religioso y nacional, una gran carga emocional ${ }^{21}$.

Los estudiosos hebreos Ron Barkai y Aviva Dorón encuentran un precedente del sentimiento de nostalgia por la patria lejana que se expresa en los Poernas de Sión en los escritos de geógrafos e historiadores sirios descendientes de los llegados a al-Andalus en el año 754, tras ser desterrados de Siria como consecuencia de la revolución abasi ${ }^{22}$. Este sentimiento alcanza su mayor expresión en algunas composiciones poéticas de autores sirio-andalusies, en las que Siria es presentada como la tierra perfecta por excelencia, y al-Andalus es concebida como un destierro temporal que, pese a sus excelencias, no podia hacer olvidar la tierra de origen, a la que añoraban regresar. Un excelente ejemplo de la poesia sirio-andalusi de añoranza es el poema conocido como ;Ay, palmera!, que se ha atri-

19 Prólogo de Fernando Díaz Esteban al libro de Aviva Dorón. Yehudah ha-Levi. Repercusión de su obra, pág. 27. Véase de este mismo autor el trabajo titulado «La lengua del Paraiso", en Anuario de Filologia, 8 (1982), págs. 111-135 (en particular, págs. 125 y ss.)

20 José Ma Millas Valílcrosa, Yehudá ha-Levi como poeta y apologista, pág. 191.

21 Aurora SalvatierRa, La muerte, el destino y la enfermedad en la obra poética de $Y$. ha-Levi y $S$ Ibn Gabirol, pág. 56.

22 Ron BaRkal y Aviva Dorón, «Mi corazón en el Oriente y yo lejos de la tierra de las palmeras. La poesia de añoranza andaluza musulmana y la poesia de Sión de Yehudah ha-Levì. 
buido a Abd al-Malek ibn Amar, nieto del califa omeya Marwan I ibn al-Hakam (684685), que fue uno de los primeros acompañantes de Abd al-Rahmán I en la península lbérica:

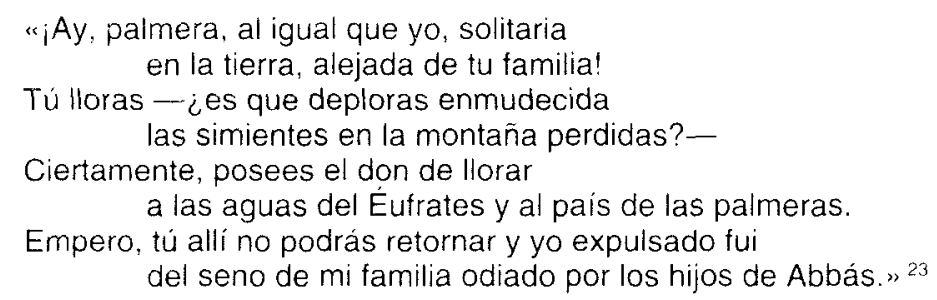

Como en las composiciones poéticas sirio-andalusies, las Siónidas manifiestan bien la íntima unión existente entre el sentimiento individual del poeta y la memoria colectiva del pueblo hebreo. Las Siónidas expresan también, a un mismo tiempo, el sentimiento de nostalgia por la patria lejana y por las virtudes atribuidas a esa tierra como morada de Dios; pero no sólo expresa el dolor por la lejanía de Israel, sino también la esperanza en un próximo retorno. Así, en tanto que en otros poetas hebreos la imagen de Jerusalén aparece como algo remoto, sentido de forma mística e intelectual, en Yehudah ha-Levi se manifiesta como un sentimiento intenso de redención. Como señala Millás Vallicrosa, Ha-Leví anhela la restauración del culto judío y del pueblo hebreo en la Tierra Prometida, de forma que se fundieran culto, pueblo y tierra en la unidad de la vida bíblica; se trataba, por tanto, de una restauración nacional, si bien supeditada a los fines religiosos de carácter universal de que era depositario el pueblo judio ${ }^{24}$.

Unos decenios después del traslado a Tierra Santa de Yehudah ha-Leví tuvo lugar el viaje a Jerusalén de otro célebre judio tudelano, Rabi Benjamin de Tudela, quien dejó un magnífico relato de su periplo, titulado Séfer Masa'ot shel Rabbi Binyamin (= Libro de viajes de Rabí Benjamín) ${ }^{25}$. Pero los motivos que impulsaron a Rabi Benjamín a emprender un viaje de tales proporciones (desde Navarra llegó hasta Bagdad, a través de Provenza, Italia, Constantinopla y Palestina) parecen haber sido de índole comercial y no propiamente religiosa. En cualquier caso, la narración de su viaje se hace particularmente pormenorizada al tratar sobre Palestina, y muy en especial al relatar su estancia en Jerusalén, lo que es un claro indicativo de su interés por Tierra Santa, pese a que su viaje no pueda considerarse, propiamente, una peregrinación. En definitiva, el libro de Rabí Benjamín ofrece una valiosisima información acerca de las regiones que atravesó y que, normalmente,

\footnotetext{
23 Ron Barkal y Avova Doron, "Mi corazon en el Oriente y yo lejos de la tierra de las palmeras. La poesía de añoranza andaluza musulmana y la poesia de Sión de Yehudah ha-Leví», pág. 243.

24 José Ma MILlas VAllichosa, La poesía sagrada hebraicoespañola. Madrid. Consejo Superior de Investigaciones Cientificas, 1940, pág. 101.

25 La mejor edición de este libro es la realizada por José Ramón Magdalena NOM de DEu, Libro de Viajes de Benjamin de Tudela. Versión castellana, introducción y notas por José Ramón Magdalena Nom de Deu. Barcelona. Riopiedras Ediciones, 1989.
} 
es veraz y objetiva; sin duda alguna, el mayor interés del relato se centra en los datos que facilita sobre las comunidades hebreas de las ciudades que visita, así como sobre los grandes centros artesanales y mercantiles de Occidente y Oriente $y$ las principales rutas mercantiles.

En el siglo xIII se incrementó el número de judíos que se dirigian a Tierra Santa procedentes de distintas regiones de la Europa occidental, como consecuencia de las crecientes dificultades socio-políticas que comenzaban a padecer, y que venían a unirse a los numerosos peregrinos que llegaban desde Damasco, Babilonia y Egipto con ocasión de las fiestas de Pésah, Shavu'ot y Sukkot. A fines del siglo Xill, Nahmánides decía en una carta a su hijo que

"muchos hombres y mujeres llegan a Jerusalén desde Damasco, Babilonia y sus proximidades a ver el emplazamiento del Templo Santo y a lamentar su destrucción” 26 .

Especial relevancia debió tener la emigración a Israel en el año 1211 de alrededor de trescientos sabios y rabinos hebreos de Francia e Inglaterra, a los que siguieron otros grupos de judíos. Muchos de ellos se establecieron en Jerusalén, constituyendo sociedades con el fin de apoyarse mutuamente ${ }^{27}$.

En 1267 llegó a Jerusalén otro sefardí notable, Rabí Mosheh ben Nahmán (1195-1270), más conocido como Nahmánides, un miembro destacado de la aljama hebrea de Gerona, en la que ejercia como rabino. Talmudista, cabalista y comentarista bíblico, tuvo una intervención relevante en la llamada Disputa de Barcelona, de 1263, en la que tuvo como principal contrincante al converso Paulo Christiano. Desde su llegada a Jerusalén, Nahmánides se esforzó por restaurar la comunidad judia de esta ciudad, que había desaparecido prácticamente en 1260 después de que los mongoles invadieran Palestina y destruyeran la ciudad santa; muchos judios murieron como consecuencia del ataque mongol, y los restantes se trasladaron en su mayor parte a Siquem, en Nablus (Cisjordania). A este fin, promovió la reparación de una antigua residencia para peregrinos judíos y su transformación en sinagoga, así como la apertura de una yeshibah, que atrajo a numerosos estudiantes jóvenes procedentes de las comarcas situadas al otro lado del río Éufrates.

Desde unos años antes de su partida hacia Tierra Santa, aún en Sefarad, Nahmánides expresaba en su obra literaria su anhelo por acudir a Jerusalén. Ya en Palestina, y al final de su Comentario a la Torah, canta las alabanzas de Jerusalén e informa a los exiliados de Sefarad acerca de la esplendidez y la santidad del país de Israel, así como de la degradación que sufre por la ausencia de sus hijos, todo ello, probablemente, con el fin de animarles a trasladarse a Tierra Santa. Así, señala a Jerusalén como el lugar

26 Encyclopaedia Judaica, vol. 13, pág. 513, voz "pilgrimage»

27 H. H. Ben Sasson, Op. cit., págs. 551-552. 
«donde estaba firmemente asentado el mundo y donde los fundamentos y los límites de la tierra comenzaron a ramificarse.... de donde surgió la profecía y se extendió hacia el alma de sus hijos - Israel-.... De ahi extrae Israel su elevación y su permanencia... y ahi es donde el monte del Templo es grande y sagrado, consagrado para el santuario... Esto es realmente lo menos que se puede decir en alabanza de la ciudad... Y hoy he visto su santidad y también una penosa visión. Encontré dentro de la ciudad un judio oprimido y sufriente; es tintorero y está lleno de desprecio. En su casa se reúnen grandes y pequeños, no alcanzando a formar un grupo suficiente para $\operatorname{orar}^{28}$. No hay bastantes personas para formar una comunidad, ni entre los ricos y los propietarios, y ni aún entre los pobres y los necesitados... Te comparo con una mujer a quien se le ha muerto su hijo de pecho; la leche le produce dolor, y amamanta cachorros... Tus mismos enemigos te compadecen, te recuerdan épocas anteriores y glorifican la ciudad santa, diciendo: Nos la entregan como herencia. Y cuando van a visitarte y encuentran todo lo que deleita la vista, corren como si huyeran del enemigo cuando no hay nadie para perseguir. Sí, está todo abandonado, toda la tierra, espaciosa y fértil, porque no son dignos de ti, y tú no eres suelo para sus plantas» ${ }^{29}$.

Nahmánides falleció en 1270, siendo enterrado en la ciudad de Haifa, junto a la tumba de Yehiel ben Yosef de París, quien había fallecido alrededor del año $1265^{30}$. Pese a la brevedad de su estancia en Palestina, su acción fue decisiva en orden a la restauración de la comunidad hebrea jerosolimitana, que sustentó firmemente sobre la Torah.

Nahmánides es un fiel reflejo del sentimiento de añoranza por Tierra Santa que en la segunda mitad del siglo xlli crecía entre los judios hispanos de forma simultánea a los cada vez mayores interrogantes sobre el exilio y el Mesías, lo que tiene mucho que ver con el progresivo declive de su posición socio-política. De este modo, entre los siglos XII al XIV se manifiesta en los sectores intelectuales hispanohebreos un creciente interés por los problemas del exilio, la redención y la santidad de Israel; este sentimiento tiene su reflejo en la obra de los intelectuales de orientación mística (cabalistas) y en la de los racionalistas; unos y otros ejercian una considerable influencia sobre la comunidad judía, a la que transmitieron sus emociones acerca de Tierra Santa, lo que contribuyó, en cierta medida, a un incremento de las migraciones hacia el Próximo Oriente.

\section{LOS MOVIMIENTOS MIGRATORIOS HACIA TIERRA SANTA EN LOS SIGLOS XIII AL XVI}

Pese a que la documentación medieval ofrezca algunas noticias acerca de grupos de judíos que desde distintos ámbitos de la Europa occidental se dirigieron a

\footnotetext{
28 Se refiere al minyán, es decir al número mínimo de diez varones mayores de trece años necesario para la oración pública.

29 H. H. Ben Sasson, Op. cit., págs. 627-628.

35 Gran conocedor del Talmud y de la Tosefta (= "complemento", "adición": colección de tradiciones tanaítas no recogidas en la Mishnah), intervino en la disputa religiosa celebrada en Parıs en tiempos del rey San Luis IX frente al judeoconverso Nicolás Donin. En 1260 emigró a Acre, donde ejerció como director de una academia rabínica.
} 
Tierra Santa, no cabe hablar en ningún momento de movimientos multitudinarios, que no hacian posibles la enorme distancia para aquella época y las dificultades que comportaba un viaje de tales características. En cualquier caso, el impacto que el retorno de ciertos grupos a Israel causaba en la memoria colectiva del conjunto de la comunidad hebrea en el exilio debia ser de una honda significación, sobrepasando con creces las dimensiones reales del fenómeno.

En 1286, el cabalista Rabí Meir ben Baruk de Rothenburg ${ }^{31}$, indignado con las enormes cargas fiscales que pesaban sobre los judíos del Sacro Imperio Romano Germánico, organizó un movimiento migratorio hacia Tierra Santa. Pero fue detenido en Lombardía y conducido a prisión, donde murió algún tiempo después, por el temor del emperador a que se produjera una huida masiva de la población hebrea ${ }^{32}$.

A lo largo de los siglos XII y XIII, los inmigrantes judíos en Palestina se establecieron, preferentemente, en la zona de dominio cristiano, en la franja litoral, donde algunas ciudades, como Acre y Tiro, conocían una intensa actividad comercial. Tras la caída de Acre en poder de los mamelucos en 1291, lo que puso fin a la presencia de los cruzados en Palestina, comenzaron a desarrollarse algunas comunidades hebreas en el interior de Palestina - Jerusalén, Ramle, Lydda, Tiberíades, Safed-, si bien la anarquía política y el caos económico que caracterizan el periodo mameluco acarrearon un deterioro en las condiciones de vida de los judíos. No obstante, a lo largo de todo el siglo xiv está documentada la llegada de sucesivos grupos de inmigrantes judíos, que propiciaron una renovación espiritual y material de las comunidades hebreas palestinas.

En los reinos hispánicos, las persecuciones que en 1391 asolaron buena parte de las comunidades judias renovaron el movimiento migratorio a Tierra Santa ${ }^{33}$. Algunos grupos de judíos castellanos atravesaban el reino de Aragón, con el fin de embarcarse en distintos puertos de Cataluña y Valencia con dirección a Palestina; al parecer, en la academia que dirigia en Zaragoza el célebre filósofo antirracionalista Hasday Crescas (1340-1412) se expedian cartas de recomendación para otras comunidades hebreas a judíos que tenían el propósito decidido de emigrar a Palestina ${ }^{34}$. En 1392 partió desde el puerto de Barcelona un barco con dirección a Alejandría y Beirut, que fue interceptado por orden regia ya que, además de judíos, viajaban en él también varios judeoconversos con el fin de retornar al judaísmo en

31 Se trata de un famoso halakista alemán, cuyas responsa y novellae sobre el Talmud fueron muy utilizadas en épocas posteriores.

32 Carlos del Valle Rodriguez, El mundo judio. Madrid. Universidad Nacional de Educación a Distancia, 1976, pág. 58.

33 Véase sobre este particular, B. DinuR, "The emigration from Spain to Eretz Yisrael after the Disorders of 1391 " (en hebreo), en Zion, XXXII (1967), págs. 161-174.

34 Esta decidida actitud obedeceria, sin duda, al impacto que debió causar al célebre rabino y teólogo de origen barcelonés el asesinato de un hijo suyo en los disturbios antijudios de 1391 en Barcelona. Pasados los criticos momentos de la persecución. Hasday Crescas se esforzó por evitar las conversiones de judios al cristianismo, y puso todo su empeño en el resurgimiento de las comunidades hebreas (Yitzhak BaEr. Historia de los Judíos en la España Cristiana. Madrid. Altalena, 1981. 2 vols. (en concreto, vol. Il, pág, 433). 
Tierra Santa. Entre los judios que por entonces emigraron a Palestina cabe destacar al anciano astrónomo mallorquín Rabi Yishaq Nifoci, quien se había ocupado de la fabricación de astrolabios en la corte de Pedro IV de Aragón y en la casa del infante don Juan; convertido al cristianismo, emprendió viaje a Tierra Santa, ya con edad avanzada, con el ánimo de retornar al judaismo ${ }^{35}$.

Como es habitual en el judaísmo en épocas de persecución, las comunidades judias hispanas vivian inmersas a fines del siglo xiv en un ambiente de expectación mesiánica, en abierto contraste con el abatimiento en el que habían caido los círculos intelectuales. No son muchas, sin embargo, las noticias que se han conservado acerca de este repunte del mesianismo popular, algunas de las cuales están asociadas a la figura de Hasday Crescas quien, según denunció Jerónimo de Santa Fe al comienzo de la llamada Controversia de Tortosa (1413-1414), habria predicado que el Mesias había nacido en la localidad palentina de Cisneros; del mismo tiempo se conserva noticia de una carta dirigida a Hasday Crescas, en la que se le pide que actúe contra los visionarios que estaban alterando a la comunidad hebrea. Del mismo modo, en su Or Adonay (= Luz del Señor) ${ }^{35}$ se encuentran algunas referencias que dan idea del interés que por entonces existía entre los judíos hispanos por la situación política de Palestina, sujeta al gobierno de los mamelucos ${ }^{37}$. Asimismo, en un opúsculo sobre la fe cristiana escrito en 1416 por maestre Juan el Viejo, un converso toledano, se mencionan diversos cálculos escatológicos que no se habían cumplido, y entre ellos el de Rabí Yishaq Abendino quien, basándose en la gematría ${ }^{38}$ del versículo de Habacuc 2.3, habría predicho que la venida del Mesías tendria lugar en el año $1391^{39}$.

A mediados del siglo $x v$ se produjo en las comunidades judias hispanas un importante rebrote del mesianismo popular, que debe ser puesto en relación con la caída de Constantinopla en poder de los turcos en 1453; los visionarios y quienes se dedicaban a los cálculos escatológicos en el judaísmo vieron en el derrumbe del Imperio Bizantino una señal incuestionable que anunciaba la inminente venida del Mesias.

El Fortalitium fidei (1460), una obra en la que fray Alonso de Espina recopila las acusaciones vertidas contra los judíos en toda la Europa occidental desde los siglos de la Plenitud medieval, ofrece valiosas noticias acerca de este despertar del mesianismo en las comunidades judias hispanas, así como sobre grupos de judeoconversos que salían de los reinos hispánicos con dirección al Próximo Oriente, con el fin de retornar alli al judaismo. En 1464 fueron detenidos en Valencia numerosos judeoconversos que habian embarcado con destino a Damasco; en el

35 Yitzhak BAER, Op. cit., vol. II, pág. 740, nota 60

36. Obra escrita en 1410, y en la que Hasday Crescas trata acerca de las raices de la Torah refutando los argumentos expuestos por Maimónides en su Guia de perplejos.

37 Yitzhak BAER, Op. cit., vol. II, págs. 434-435.

38 Ciencia de la interpretación de un texto sagrado segun el valor numéricc de las letras de las palabras. Se utilizó mucho durante la Edad Media por parte de los cabalistas, y en época moderna por los seguidores de Sabbetay Sebi.

39 Yitzhak BAER, Op. cit, vol. II, págs. 433-434. 
proceso inquisitorial que se siguió contra ellos, se hace alusión a unas cartas llegadas desde Sicilia en las que se daría cuenta de otras setenta familias de judeoconversos valencianos que se habian trasladado a la ciudad albanesa de Valona, donde habian retornado al judaismo ${ }^{40}$.

El Fortalitium fidei hace referencia también a unas cartas, supuestamente llegadas desde Constantinopla, en las que se insistía en la próxima venida del Mesias, y da noticia de distintas versiones que acerca de su llegada corrian entre los judios y los judeoconversos hispanos; en estas profecías se identificaba a los turcos con el Anticristo, que destruia las iglesias cristianas y que, por el contrario, hacía mucho honor a los judíos y a sus sinagogas. Por todo ello, en dichas cartas se animaba a judíos y judeoconversos a trasladarse a Constantinopla, donde encontrarían todos los bienes que dejaban en Sefarad, en tanto que los que permanecieran aquí no tendrian ni para comer, ya que iba a producirse un gran derramamiento de sangre ${ }^{4 !}$.

Todas estas profecias, que corrian de boca en boca, debieron producir una enorme conmoción en las comunidades de judios y judeoconversos, animándose unos a otros a elaborar proyectos para trasladarse en grupo al Próximo Oriente.

La caída de Constantinopla en poder de los turcos coincidió en el tiempo con la aparición de un cometa, lo que contribuyó a reforzar la creencia, generalizada en algunos círculos de judeoconversos, en torno a la venida del Mesias en Oriente. Haim Beinart ha estudiado la incidencia que este fenómeno tuvo en la comunidad judeoconversa de Ciudad Real, a través de un análisis exhaustivo de los procesos inquisitoriales promovidos a fines del siglo $x V$ contra varios judeoconversos vecinos de esta ciudad. Estos procesos ponen de manifiesto que los judeoconversos se reunian en la casa de Sancho de Ciudad, uno de los miembros más destacados de la comunidad judeoconversa, para conversar acerca de los acontecimientos políticos que estaban teniendo lugar en Oriente, así como sobre el significado del cometa que habia aparecido en el cielo. Es ilustrativa del sentimiento que reinaba en aquel momento entre los judeoconversos de Ciudad Real la declaración de Catalina Fernández, quien afirma que

«... vido que estavan muchos conversos e conversas desta çibdad ençima de la torre de Sancho de Çibdad mirando aquella señal de aquella estrella, e que dezian grandes apellidos ya que nasçido es el que nos ha de salvar» ${ }^{42}$.

La huida de judeoconversos hispanos hacia el Próximo Oriente no fue algo inusual a lo largo de la segunda mitad del siglo xv, viéndose favorecida tanto por la

40 Yitzhak BAER, Op. cit., vol. II, págs. 540-541.

41 Yitzhak BAER, Op. cit., vol. Il, págs. 451-542.

42 Archivo Histórico Nacional, inquisición de Toledo, leg. $\mathrm{n}$ 145. Haim BEINART, Records of the Trials of the Spanish Inquisition in Ciudad Real. Jerusalem, 1974-1981, 4 vols. (en concreto, vol. 1); Los conversos ante el tribunal de la Inquisición. Barcelona. Riopiedras Ediciones, 1983, pág. 73, nota 44. 
expectativa mesiánica como, principalmente, por el temor ante los motines anticonversos que sufrieron diversas ciudades castellanas. Unos huían a través de la frontera del reino de Granada, embarcando en el puerto de Málaga, y otros lo hacian a través del reino de Aragón, embarcando en algún puerto de Cataluña o de Valencia, en ambos casos con rumbo al Próximo Oriente. El movimiento migratorio se incrementó de forma considerable en los años ochenta del siglo xv, a raíz de las primeras actuaciones del tribunal de la Inquisición; todo parece indicar que, incluso, hubo propaganda animando a los judeoconversos a huir hacia el Próximo Oriente para retornar alli al judaísmo.

Pero este movimiento migratorio hacia el Próximo Oriente de los judíos y judeoconversos hispanos se engloba en un fenómeno más amplio que afecta a otras diversas áreas de la Europa occidental, en particular a la península Itálica. Desde hacía mucho tiempo, las comunidades hebreas italianas mantenían estrechos contactos con las de Palestina, interesándose por su devenir histórico. De este modo, en los responsa ${ }^{43}$ del judio italiano Rabí Yosef Colón se contienen noticias acerca del envío regular de contribuciones económicas a Jerusalén por parte de las comunidades judías italianas, que disponian, incluso, de unos oficiales especiales nombrados con el fin de proceder a la recaudación de las cantidades correspondientes.

A fines del siglo $x v$ se reforzaron los lazos de unión entre las aljamas italianas y las palestinas, lo que se vio favorecido por los viajes que en los años ochenta realizaron a Tierra Santa algunas destacadas figuras del judaísmo italiano, como Rabi Mesullam de Volterra o Rabi Obadyá ben Abraham de Bertinoro (c ${ }^{a} 1450-c^{a}$ 1516) ${ }^{44}$, quienes dejaron por escrito las impresiones que habian obtenido acerca del estado de las comunidades hebreas palestinas ${ }^{45}$.

Por último, cuando en 1492 y en 1497 se produce la expulsión de los judios de Castilla y la Corona de Aragón y de Portugal, respectivamente, una importante corriente de judios hispanos y portugueses se dirigió hacia el Próximo Oriente. La llegada de los sefardies tuvo lugar en tres oleadas, principalmente: la primera en los años siguientes a la salida de España y de Portugal; la segunda y más numerosa, unos decenios después, fue protagonizada por grupos de judios que se habian establecido inicialmente en Italia o en el Magreb; y la tercera fue la integrada por grupos de judaizantes portugueses que huían de la Inquisición.

La proximidad de Tierra Santa al Imperio Otomano, y la favorable acogida que les dispensó el sultán turco Bayaceto ${ }^{4}{ }^{46}$, hizo de los antiguos territorios bizantinos

${ }^{43}$ Respuestas dadas a preguntas sobre cualquier aspecto de la ley judia por parte de las autoridades rabínicas, desde tiempos de los gaones hasta la actualidad.

${ }^{44}$ Rabino italiano y comentarista de la Mishnah; su comentario es uno de los más consultados para la interpretación del texto misnaico, y se reproduce en casi todas las ediciones de la Mishnah.

${ }^{45}$ H. H. Ben SASSON, Op. cit., págs. 671-672.

${ }_{46}$ Los sefardies terían fama de competentes en el ejercicio de diversas actividades hacendísticas, artesanales y mercantiles, por lo que las autoridades otomanas los consideraron un factor potencial de desarrollo económico y tecnológico. 
un lugar de refugio especialmente atractivo para los judios sefardíes. La protección imperial y la promulgación de la orden que otorgaba a los sefardies el derecho de residencia en el Imperio Otomano tuvieron también mucho que ver con la decisiva mediación de los dirigentes de las comunidades hebreas autóctonas quienes, además, procuraron ayuda material a los inmigrantes que llegaban en peores condiciones. De este modo, al poco tiempo de su llegada, los sefardíes constituyeron algunas comunidades importantes, entre las que sobresalen las de las ciudades de Constantinopla (Estambul), Salónica, Adrianópolis y Esmirna, todas ellas pujantes centros mercantiles ${ }^{47}$.

Otros grupos de sefardies se establecieron en distintas localidades palestinas. La incorporación de Palestina al Imperio Otomano, en el año 1516, propició un importante desarrollo económico de las ciudades del litoral a lo largo del siglo XVI, del que se favorecieron también en buena medida las comunidades hebreas.

Los dos grandes centros de la inmigración sefardi en Palestina fueron Jerusalén y, principalmente, Safed, ciudad ésta que se transformó en el siglo Xvi en un emporio económico y en un gran centro religioso y cultural. Varios fueron los motivos que pudieron contribuir a la elección de Safed como lugar de inmigración preferente de los sefardies en Palestina: su posición estratégica, en las proximidades de Siria y en la ruta por la que desde el noroeste del Imperio Otomano los judíos se dirigían en peregrinación a Jerusalén; la falta de interés religioso de cristianos y musulmanes por esta ciudad, que no era para ellos lugar sagrado; y el aura de santidad que Safed tenía para los judíos, pues en sus proximidades se localizaban las tumbas de diversos tannaim ${ }^{48}$, entre las que sobresalía la de Simeón ben Yohay ${ }^{49}$ en la localidad de Merom ${ }^{50}$.

En el segundo cuarto del siglo xvı la comunidad hebrea de Safed experimentó un importantísimo crecimiento demográfico, del que nos dan cuenta algunas fuentes de la época. En la crónica de la que es autor el judio italiano Mosheh Bassola de Ancona, en la que narra el viaje que realizó por Palestina entre 1521 y 1523, se señala que por estas fechas residian en Safed unas trescientas familias judias, que era un número similar al de la comunidad hebrea de Jerusalén. Tres decenios después, en 1551, un viajero no judío que visitó Safed fijaba entre ocho y diez mil el

: Una buena aproximación a la historia de la presencia setardi en el Imperio Otomano es la de Jacob BARNAI, "Los sefardies en el Imperio Otomano (siglos XV-XIX)", en Maria Antonia BEL Bravo (Coordinadora), Diaspora Sefardi. Madrid. Editorial Mapfre, 1992. págs. 91-165.

"* Término arameo que puede traducirse por "maestros" (en singular, tanna). Asi se denomina a los antiguos sabios y maestros del judaismo de los siglos I y 4 d.C., que fueron fundamentales para la aparición del movimiento rabinico por su estudio de la ley judia (Torah) y la formulación de la parte central de la ley oral (Mishnah y Midrashim).

44 Tanna palestino del siglo "I.C.; es uno de los cinco discípulos de Akiba que sobrevivieron al fracaso de la rebelión de Bar Kochba (132-135 d.C.). Tradicionalmente se le ha considerado el autor del Zohar, un comentario mistico a la Torah y a partes de los Hagiógrafos, si bien la mayor parte de los investigadores lo atribuyen realmente a quien primero lo publicó, el cabalista castellano Mosheh ben Shem Tob de León (1250-1305).

iv H. H. BEN-SASSON, Op. cit., pág. 744. 
número de judíos que residian en esta ciudad; entre ellos tenían un peso muy especial los sefardies, de forma que a lo largo del siglo XVI la lengua usual en esta ciudad era el castellano ${ }^{51}$.

Desde el punto de vista económico, Safed sobresalió a lo largo del siglo XV como centro de un activo comercio de grano y de productos textiles entre Palestina, Siria y Libano, asi como por su industria textil, lo que abría enormes posibilidades a artesanos y pequeños mercaderes.

Por lo que respecta a la cultura, en la centuria décimosexta residieron en Safed algunas de las figuras más destacadas de la intelectualidad hebrea del momento, como el cabalista palestino Rabi Yishaq ben Shelomoh de Luria (1534-1572), cuyas ideas influyeron profundamente en la evolución del misticismo judio; el toledano Rabí Yosef Caro (1488-1575), codificador talmúdico y autor del Sulhan Aruk (= Mesa Preparada), una recopilación abreviada de la ley judia (Halakah) que se convirtió en código legislativo autorizado para el judaísmo ortodoxo; o el también toledano Yaaqob Berab, quien protagonizó, junto con Rabi Yosef Caro, un intento fallido de restauración del Shanedrin ${ }^{52}$.

Otros grupos de sefardies se dirigieron hacia Galilea, dando lugar a la conformación de algunas pequeñas comunidades de carácter rural. Pero el grupo más numeroso se concentró en la ciudad de Tiberíades, que fue revitalizada en un ambiente de marcado mesianismo, bajo la dirección de una acaudalada familia de judíos de origen portugués, los Nasí, quienes lograron hacerse con el favor de las autoridades otomanas. Su proyecto de reconstrucción de Tiberíades, para el que contaron con la colaboración de numerosos artesanos sefardies, fue dirigido por don Yosef Nasi Mendes ( $\left.c^{a} 1524-1579\right)$ y su tía doña Gracia Nasí. Don Yosef nació judeoconverso en Portugal, y en 1537 acompañó a su tía doña Gracia a Amberes, donde permanecieron hasta 1545, año en el que se trasladaron a Venecia; en el año 1553 se establecieron en Estambul, donde don Yosef se convirtió al judaísmo y contrajo matrimonio con Reyna, hija de doña Gracia. De la importancia de estos personajes da buena idea el hecho de que la autorización del dux de Venecia para que pudieran abandonar el ducado fue otorgada a petición del sultán otomano Selim II, quien en 1556 concedió a don Yosef el título de duque de Naxos y de las Cícladas. Don Yosef alcanzó una considerable influencia en la corte otomana, de forma que con frecuencia los embajadores de estados europeos recurrian a él como mediador ante el sultán ${ }^{53}$.

En 1560, con la aquiescencia del sultán y de las autoridades otomanas, don Yosef y doña Gracia arrendaron del gobernador de Damasco la ciudad de Tiberiades y siete aldeas de sus alrededores, por una cuantía de mil piezas de oro anuales, con el fin de promover su repoblación con judíos. Era una comarca especial-

51 Carlos del Valle Rodriguez, El mundo judio, pág. 61.

5. Asamblea de 71 ancianos que actuaban como la corte y la asamblea legislativa supremas judias durante el periodo rabínico. Dejó de actuar antes del siglo IV d.C.

53 H. H. BEN SASSON, Op. cit, págs. $746-747$ y $772-773$. 
mente apta para el cultivo de la caña de azúcar, así como del árbol de morera, lo que propiciaria un considerable desarrollo de la manufactura de la seda. Asimismo, don Yosef impulsó la restauración de los antiguos baños de la ciudad, que se abastecian de las fuentes de agua caliente ubicadas en las proximidades del lago de Tiberíades, con la idea de atraer a un importante número de visitantes no sólo judíos, sino también musulmanes y cristianos.

Con el fin de proceder a la repoblación de Tiberíades, don Yosef escribió a los dirigentes de las principales comunidades hebreas del ámbito mediterráneo, principalmente de la península Itálica, reclamando el envio de pobladores, en particular de artesanos. Para su traslado a Galilea, don Yosef contrató varios buques y compró grandes cantidades de alimentos en Venecia y Ancona. El capitulo 187 del Emeq ha-Bakha (= El Valle del Llanto), una crónica hebrea del siglo xvI de la que es autor el judío de origen español Yosef ha-Kohén (1496-1577), está dedicado íntegramente a narrar la experiencia de restauración de Tiberiades ${ }^{54}$.

El proyecto de don Yosef Nasí combinaba el impulso repoblador y colonizador con unos indudables anhelos mesiánicos, de forma que se promovía el establecimiento de una colonia judía en la tierra en la que, según la tradición judia, tendría lugar la venida del Mesias y la redención de Israel. Como es fácil deducir de algunas referencias de autores de fines del siglo $x I x$ y de comienzos del siglo $x x$, como David Kaufmann (1852-1899) ${ }^{55}$, el naciente sionismo de esa época, que aspiraba a hacer de Palestina la patria judía, recordaba aún con nostalgia el proyecto colonizador de Tiberíades, utilizándolo como argumento de su acción política.

En definitiva, la empresa fue dirigida por algunas poderosas y acaudaladas familias judías italianas, si bien muchas de ellas de origen español, y fue llevada a cabo con numerosos artesanos, también en su mayor parte sefardíes, quienes impulsaron el desarrollo de una artesanía sedera y textil, para lo que se procedió a la construcción de numerosas plantaciones para la cría de gusanos de seda y a la importación de lana de tipo merino de origen castellano.

A la muerte de don Yosef Nasí, en 1579, la empresa fue proseguida por Shelomoh Abenaes, duque de Mitilene, otro destacado cortesano judio de Estambul, originario también de la península Ibérica.

Pero tanto Safed como Tiberíades entraron en una grave crisis económica, espiritual y cultural a fines del siglo XVI, lo que motivó el traslado de muchos de sus pobladores a ciudades de Turquía y de Egipto; por este motivo, Jerusalén volvió a ser a lo largo del siglo XVII el centro más importante del judaísmo palestino ${ }^{56}$.

54 Una excelente edición de esta crónica en: YOSEF HA-KOHEN, El Valle del Llanto (Emeq ha-Bakha). Crónica hebrea del siglo xvi. Introducción, traducción y notas por Pilar León Tello. Barcelona. Riopiedras Ediciones, 1989 (capitulo 187, págs. 164-165).

Graduado por el seminario judio alemán de Breslau, fue uno de los primeros maestros de la escuela rabínica de Budapest, y una de las más destacadas figuras de la intelectualidad judia en la Europa de la segunda mitad del siglo XIX.

Jacob BARNAI, "Los sefardies en el Imperio Otomano (siglos XV-XIX)", pág. 113. 
Pese al fracaso de la empresa, la reconstrucción de Safed y Tiberíades supuso una restauración transitoria de la actividad económica, de la creación intelectual y del sentimiento religioso judío en Tierra Santa, que serviria de modelo y de fundamento para proyectos posteriores.

\section{CONCLUSIÓN: LA EMIGRACIÓN JUDIA A PALESTINA EN LOS SIGLOS XVII AL XIX}

En el siglo XVII las condiciones de vida se hicieron especialmente difíciles en Palestina, lo que influyó en un estancamiento demográfico de la población hebrea, al disminuir la inmigración ${ }^{57}$. A mediados de esta centuria podían ser unos quince mil los judios que residían en Palestina, y de ellos algo más de la cuarta parte lo hacian en Jerusalén; por entonces, la comunidad hebrea de Safed había visto reducidos drásticamente sus efectivos demográficos, y la ciudad de Tiberíades se encontraba totalmente asolada a causa de la crisis económica provocada por los enfrentamientos entre las tribus autóctonas, y su comunidad hebrea había emigrado en su práctica totalidad ${ }^{58}$.

Durante todo el siglo XVII el peso sustancial del judaísmo palestino siguió correspondiendo a los sefardíes de origen español, llegados en su mayor parte desde Turquia y los Balcanes, y que habian logrado hacerse con el control de las comunidades ciudadanas por su mayor preparación intelectual y religiosa. Sólo algunas comunidades, en particular las establecidas en distintas aldeas de Galilea, mantuvieron el carácter arabizante previo a la inmigración sefardí.

En esta misma centuria, y debido a las crecientes dificultades económicas que conocieron las comunidades hebreas palestinas, se ensayó un sistema de subsistencia basado en las aportaciones realizadas por las comunidades judias de la Diáspora (más tarde conocido como haluqqah), y que serviria de modelo para proyectos posteriores en el tiempo ${ }^{59}$.

Desde el siglo XVIII se constata una creciente inmigración de judíos ashkenazíes, procedentes de la Europa central y oriental, que daría lugar a una alteración sustancial en el poblamiento hebreo en Palestina, que hasta entonces había sido mayoritariamente seíardí. Como había sucedido en el siglo XVII con las inmigraciones de inspiración sabbetiana, la mayor parte de los movimientos migratorios del siglo XVIII se hicieron también bajo el signo del mesianismo ${ }^{60}$. Pero, en cualquier

\footnotetext{
57 Únicamente es de reseñar la llegada a Palestina, en la segunda mitad de esta centuria, de diversos grupos de judios, en su mayor parte procedentes de Turquia, y que eran seguidores de Sabbetay Sebi (1626-1676), un erudito originario de la ciudad turca de Fsmirna, quien se dedico al estudio talmúdico y cabalístico. En 1665 fue proclamado mesias por Natán de Gaza, lo que dio lugar a un importantísimo rebrote del fervor mesiánico. En 1666 fue apresado en Estambul, y se convirtio al islamismo para salvar su vida, lo que produjo una honda conmoción entre sus seguidores, algunos de los cuales, pese a todo, siguieron proclamándolo como mesias.

58 Jacob Barnal, Op. cit, pág. 139

59 Jacob Barnai, Op. cit., pág. 140.

60 Jacob BARNAi, Op. cit., págs. 140-141.
} 
caso, no fueron numéricamente significativos. Sólo desde comienzos del siglo xx, tras la constitución del movimiento sionista en $1897^{61}$, un número cada vez mayor de judios europeos comenzó a emigrar a Palestina, contando con el respaldo económico del movimiento sionista norteamericano y de algunos judios filántropos ingleses, como sir Mosheh Montefiore o el barón Edmond de Rothschild. Desde entonces, la migración judía adquirió también unos tintes más políticos y nacionalistas que los propiamente religiosos y mesiánicos que hasta entonces la habían caracterizado. Pero esto constituye ya parte de otro tema, también de indudable interés, pues sus consecuencias las vivimos todavía en la actualidad, pero que se aleja ya de la cuestión concreta que nos ocupaba.

61 Se considera fundador del sionismo politico a Theodor Herzl (1869-1904), escritor y periodista austríaco nacido en Budapest, quien combatió la asimilación judia en Europa y promovió la constitución de una patria judia en Palestina. En 1897 convocó en Basilea el primer congreso sionista, en el que se acordó la creación de la Organización Sionista Mundial, de la que fue elegido su primer presidente; desde este momento desplegó una intensa actividad politica encaminada a la creación de un Estado judio en Palestina, para lo que entabló negociaciones con los principales líderes mundiales. 